\title{
Evaluation of the Epidemiology, Prognostic Factors and Results of the Patients Hospitalized in the Intensive Care Unit Due to Thoracic Trauma
}

\author{
Mustafa Kuzucuoğlu' (D, Zerrin Özçelik² (D, Cenk Balta³ (1) \\ 'Department of Thoracic Surgery, İzmir Katip Çelebi University School of Medicine, İzmir, Turkey \\ ${ }^{2}$ Balıkesir State Hospital, Intensive Care Unit, Balıkesir, Turkey \\ ${ }^{3}$ Department of Thoracic Surgery, Balıkesir University School of Medicine, Balıkesir, Turkey \\ ORCID iDs of the authors: M.K. 0000-000I-9889-006I; Z.Ö. 0000-000I-576I-2022; C.B. 0000-0002-4073-8I0I.
}

Cite this article as: Kuzucuoğlu M, Özçelik Z, Balta C. Evaluation of the Epidemiology, Prognostic Factors and Results of the Patients Hospitalized in the Intensive Care Unit Due to Thoracic Trauma. Cyprus J Med Sci 2020; 5(2): 12I-5.

\section{BACKGROUND/AIMS}

We aimed to evaluate patients with thoracic trauma who were followed in intensive care unit in terms of epidemiologic, admission scoring systems, follow-up processes and prognosis.

\begin{abstract}
MATERIAL and METHODS
Patients with thoracic trauma over 18 years of age who were followed up and treated in the intensive care unit between January l, 2013 and June I, 2018 were evaluated retrospectively. Patients were evaluated in terms of age, gender, history of trauma, Glasgow Coma Score (GCS), Acute Physiology and Chronic Health Evaluation (APACHE) II score, blood gas values, intubation requirement, mechanical ventilator requirement, length of stay, survival and factors affecting prognosis.
\end{abstract}

\section{RESULTS}

Of the 30 patients included in the study, 28 (93.3\%) were male and $2(6.7 \%)$ were female. Twenty-eight (60\%) patients had blunt thorax trauma and $12(40 \%)$ had penetrating thorax trauma. Intubation was required in 20 patients and blood transfusion was required in 10 patients. The median follow-up of the trauma patients in the intensive care unit was 120 hours and the median duration of stay in the mechanical ventilator was 84 hours. A statistically significant correlation was found between APACHE II scores and duration of mechanical ventilator stay $(p=0.024)$ and $\mathrm{pH}$ and intensive care unit stay $(p=0.013)$. When the patients were evaluated in terms of survival, there was a statistically significant relationship between GCS and APACHE II scores and survival ( $p=0.00 I)$.

\section{CONCLUSION}

GCS and APACHE II scoring systems play an important role in predicting mortality in patients admitted to intensive care unit due to trauma.

Keywords: Intensive care unit, mortality, thorax, trauma

\section{INTRODUCTION}

Trauma stands out as one of the most common causes of deaths, especially among the young population, and it accounts for about $10 \%$ of all deaths in the world. However, it also leads to a high cost with the intensive care treatment requirements and morbidity it creates (1-4). Thoracic traumas can be in isolated forms; however, in patients with multi-traumas, they often accompany traumas of other systems, and approximately $25 \%$ of trauma-related deaths occur due to thoracic trauma $(5,6)$.

Various scoring methods are used to evaluate the general condition of patients followed up in intensive care units and to predict trauma-related prognosis. These scoring systems can be grouped in 2 groups as prognostic scoring systems and scoring systems for evaluating morbidity. Scoring systems for evaluating the prognosis are performed at the time of hospitalization of the patient or by evaluating the patient's data within the first 24 hours, and the aim is to determine the risk of mortality that may occur in the patient. Among these, Acute Physiology and Chronic Health Evaluation 2 (APACHE II) 
and Glasgow Coma Score (GCS) are the two most used scoring methods $(2,7)$.

In our study, we aimed to investigate the epidemiology of trau$\mathrm{ma}, \mathrm{GCS}$ and APACHE II scores of patients, intensive care follow-up processes, and the relationship between mortality and morbidity in patients with thoracic trauma hospitalized in the intensive care unit due to trauma.

\section{MATERIAL AND METHODS}

In the study, the records of patients who received inpatient treatment in Intensive Care Unit between January I, 2013 and June I, 2018 were evaluated retrospectively. Patients over 18 years old and with thoracic trauma were included in the study. The patients included in the study were evaluated in terms of age, gender, history of trauma, GCS, APACHE II score, blood gas values, intubation need, mechanical ventilator need, duration of hospitalization, survival, and factors affecting prognosis.

The normal distribution assumption of the data obtained was checked with the Kolmogorov-Smirnov test. The mean standard deviation values of the parametric variables and the median, 25 and 75 percentage of non-parametric data, and the percentages of the categorical variables were calculated as descriptive statistics. Mann-Whitney $U$ test was used for group mean comparisons. Chi-square test and Fisher's exact test were used to analyze the relationship between categorical variables. Those with a $p$ value below 0.05 were considered statistically significant. For statistical analysis, Statistical Package for the Social Sciences 22 (IBM Corp.; Armonk, NY, USA) statistics program was used.

Since our study is a retrospective study, examinations were made retrospectively on files. Therefore, informed consent forms were not obtained from the patients. In the study, Clinical Research Ethics Committee approval (Decision No: 2018/I5I) was obtained, and the biggest limitation of the study was the low number and diversity of the patients.

\section{RESULTS}

Of the 30 patients included in the study, 28 (93.3\%) were male, 2 $(6.7 \%)$ were female, and their mean age was $47.7 \pm 20.89 .18(60 \%)$ patients had blunt thoracic trauma, $12(40 \%)$ had penetrating thoracic trauma, and only $3(10 \%)$ had isolated thoracic trauma. The most common additional traumatic pathology observed in the patients was head trauma with $43.3 \%$ (Table I).

\section{Main Points:}

- We evaluated the relationship between the APACHE 2 and GCS scores of the thoracic trauma patients and the length of hospital stay, the need for mechanical ventilation and survival.

- We have shown that scoring systems are very important in determining the patient's mortality risk in trauma patients.

- The mortality risk is very high when the GKS value is below II and the APACHE 2 value is above 14 in trauma patients hospitalized in the intensive care unit, and its specificity is above $75 \%$.
While 20 of the patients included in the study needed intubation, there was no statistically significant relationship between traumatic pathology and intubation need. While 10 of the trauma patients required blood transfusion, statistical analysis revealed that blood transfusion was statistically significantly necessary for the patients diagnosed with hemothorax $(p=0.017$ ) (Table 2).

The median follow-up time in the intensive care unit of the trauma patients included in the study was 120 hours. When the intubation need of the patients and the duration of stay in intensive care unit were compared, it was found that there was no significant difference ( $p=0.812$ ), while there was a correlation between the duration of being connected to mechanical ventilator and the duration of stay in the intensive care unit in patients supported with mechanical ventilator $(r=0.462, p=0.01)$. The median duration of stay in the mechanical ventilator was determined to be 84 hours in patients with mechanical ventilator support.

GCS, APACHE II scoring, blood gas and biochemical tests were used to take the patients into intensive care and to determine the need for mechanical ventilator and follow-up. When the data obtained were evaluated statistically, it was determined that hematocrit was lower in patients with hemotho$\operatorname{rax}(p=0.020, U=55.5)$, while in patients with pneumothorax, $\mathrm{pO}_{2}$ and $\mathrm{SaO}_{2}$ mean values were lower $(\mathrm{p}=0.017, \mathrm{U}=54$ and $\mathrm{p}=0.043$, $\mathrm{U}=2.5)$, and $\mathrm{pCO}_{2}$ values were higher $(\mathrm{p}=0.004, \mathrm{U}=176.5)$. A statistically significant correlation was found between the APACHE II scores of the patients at the time of admittance to the hos-

\begin{tabular}{|c|c|c|c|c|}
\hline & & $\begin{array}{l}\text { BLUNT } \\
\text { TRAUMA }\end{array}$ & $\begin{array}{l}\text { PENETRAN } \\
\text { TRAUMA }\end{array}$ & $p$ \\
\hline \multirow[t]{2}{*}{ Heamothorax } & + & 5 & 8 & 0.035 \\
\hline & - & 13 & 4 & \\
\hline \multirow[t]{2}{*}{ Pneumothorax } & + & 9 & 4 & 0.367 \\
\hline & - & 9 & 8 & \\
\hline \multirow[t]{2}{*}{ Pulmonary contusion } & + & ॥ & 1 & $0.007^{*}$ \\
\hline & - & 7 & ॥ & \\
\hline \multirow[t]{2}{*}{ Rib fracture } & + & 9 & 5 & 0.654 \\
\hline & - & 9 & 7 & \\
\hline \multirow[t]{2}{*}{ Sternum fracture } & + & 1 & 2 & 0.320 \\
\hline & - & 17 & 10 & \\
\hline \multirow[t]{2}{*}{ Diaphragmatic laceration } & + & 0 & 4 & $0.018^{*}$ \\
\hline & - & 18 & 8 & \\
\hline \multirow[t]{2}{*}{ Head injury } & + & ॥ & 2 & 0.016 \\
\hline & - & 7 & 10 & \\
\hline \multirow[t]{2}{*}{ Abdominal trauma } & + & 0 & 7 & $0.001^{*}$ \\
\hline & - & 18 & 5 & \\
\hline \multirow[t]{2}{*}{ Cardiovascular trauma } & + & 0 & 4 & $0.018^{*}$ \\
\hline & - & 18 & 8 & \\
\hline \multirow[t]{2}{*}{ Bone fracture } & + & 7 & I & 0.099 \\
\hline & - & $\|$ & ॥ & \\
\hline \multirow[t]{2}{*}{ Facial trauma } & + & 2 & 1 & 1 \\
\hline & - & 16 & II & \\
\hline
\end{tabular}


TABLE 2. Relationship between traumatic pathologies and intubation and transfusion requirement

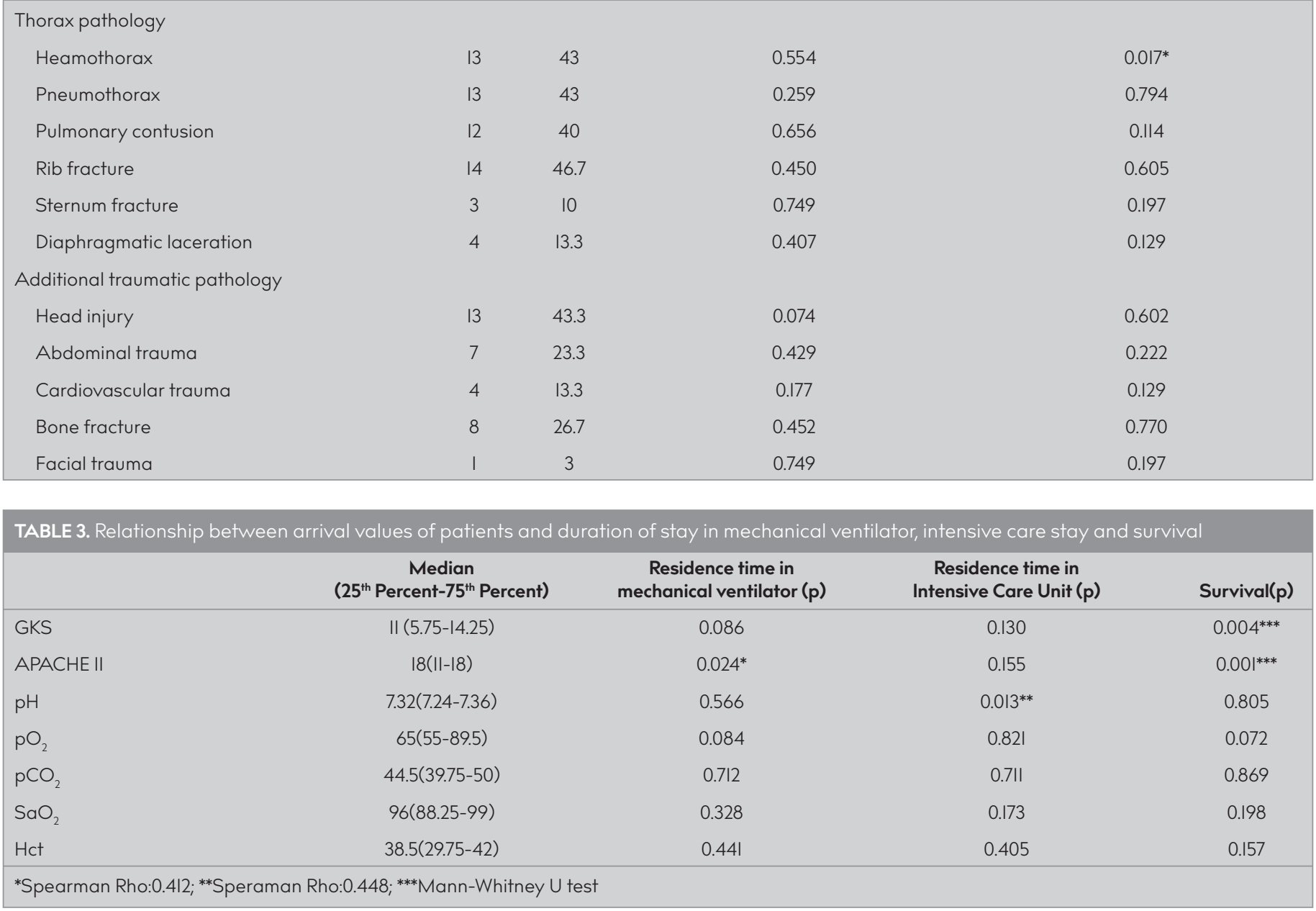

pital and the duration of their stay in the mechanical ventilator $(p=0.024, r=0.412)$ and between $\mathrm{pH}$ and the duration of their stay in the ICU $(p=0.013, r=0.448)$. When the patients were evaluated in terms of survival, a statistically significant relationship was found between the GCS and APACHE II scores and survival ( $p=0.00$ l $U=27.5 ; p=0.004 U=178$ ) (Table 3).

When the relationship between GCS and survival was analyzed through ROC analysis, it was observed that survival was negatively affected in patients whose GCS scores fell below II.5, with $72 \%$ sensitivity and $76 \%$ specificity (AUC=0.805, $p=0.005$ ). As for the relationship between APACHE II score and survival, it was found that survival was affected more negatively when the APACHE II score increased over 14.5, with $94 \%$ sensitivity and $76 \%$ specificity. ( $A \cup C=0.876, p=0.001$ ). When the duration of stay in the mechanical ventilator was longer than 18 hours, it was found that the survival rate was worse, with $82 \%$ sensitivity, $85 \%$ specificity ( $A \cup C=0.919, p=0.001$ ).

\section{DISCUSSION}

Traumas are one of the main causes of deaths, particularly in the young population in the world. Considering all age groups, although there are regional differences, traumas are one of the most common causes of death after cardiovascular diseases and cancer $(8,9)$. According to the 2013 data of Turkey Statis- tics Institute (TSI), traumas rank fifth with a $5 \%$ share among the deaths in all age groups (10). In the study conducted by Akturan et al. (II), in which they used the data of TSI between 2009-2016, traumatic deaths were reported to be in the sixth place with $4.63 \%$ in all age groups.

Thoracic traumas account for approximately $6 \%$ of all traumas and are the direct causes of death in $25 \%$ of trauma-related deaths and the concomitant cause of death in $25 \%$. Other systemic traumas accompanying thoracic traumas further increase the risk of death, and patients exposed to trauma often require follow-up and treatment in the intensive care unit (12-14).

In the study conducted by Emircan et al. (5), in which they retrospectively examined patients with thoracic trauma, the majority of patients were blunt thoracic trauma patients and the most common trauma was traffic accident related with $50 \%$. The majority of the patients were female, and $62.2 \%$ were young adults between the ages of 20-49. In the study conducted by Pogorzelski et al. (15) which included trauma patients hospitalized in intensive care unit, the most common cause of trauma was traffic accidents with $60.3 \%$, and the mean age of the patients was 33.3. In the study carried out by Abolfotouh et al. (16), which included a series of 3786 diseases, the majority of trauma patients were males. In the trauma patients with an average age of 29.6 
years, the cause of trauma was often blunt trauma, and the most common reason was traffic accidents. In our study, 93.3\% of our patients were male, and their mean age was $47.7 .60 \%$ of patients were exposed to blunt thoracic trauma.

In their study which involved 228 thoracic trauma patients, Moon et al. (17) determined that the most common pathology was pulmonary contusion with $96.5 \%$, while hemothorax, traumatic flail chest and pneumothorax were the other most common pathologies. The average number of rib fractures in patients participating in their study was found to be 10 . The study of Lin et al. (12) included 1333 patients with thoracic trauma, and 484 of these patients were treated in intensive care unit. They detected rib or sternum fractures in $79.1 \%$, hemothorax in $56.1 \%$, pneumothorax in $27.3 \%$, and pulmonary contusion in $4.1 \%$ of the patients treated in the intensive care unit. They reported the most common additional traumatic pathology in this patient group as head trauma with $52.9 \%$. In his study, Okabe (18) stated that 691 of 4317 blunt trauma patients had rib fractures due to blunt chest trauma, and 206 of these patients needed mechanical ventilation. In our study, the most common pathology was rib fracture, while the most common additional pathology was head trauma.

Various scoring systems are used to predict the prognosis of inpatients in intensive care units. Among these scoring systems, The Therapeutic Intervention Scoring System (TISS) is the first scoring system defined in 1974. In this system, where 57 parameters were evaluated when it was first defined, evaluation has been made with 19 parameters since $1997(7,19,20)$. The APACHE scoring system, calculated from 34 different variables of seven organs, was defined in 1981. The APACHE II scoring system, which is an edited version of this complex system, was defined in 1985 and is still one of the most frequently used scoring systems. GCS is also the most commonly used scoring system in intensive care unit or emergency department, especially in evalvating the neurological status of head trauma patients $(7,21)$.

In their study in which they examined trauma patients followed up in intensive care unit, Ünlü et al. (22) found the APACHE II median score as I3, GCS median score as 9, and they determined that the rate of mechanical ventilation need and mortality rates increased in patients as the APACHE II score increased and GCS decreased. In 125 patients who developed mortality, they found the median value of APACHE II score as 21 and GCS median value as 7. In their study, Yıldırım et al. (2) found the average of APACHE II scores in trauma patients with exitus status as 15 and showed that this was statistically significant. In their studies, Emircan et al. (5) and Kara et al. (I) demonstrated that GCS was statistically significantly lower in patients with exitus status than in other traumatic patients. Dur et al. (23) also found the mortality rate to be $57.6 \%$ in patients with GCS below 8 in their study. In our study, we determined that there was a statistically significant relationship between GCS and APACHE II score and the duration of stay in the mechanical ventilator and mortality of patients.

In his study, Okabe (I) analyzed the patients in 2 groups according to their duration of stay in mechanical ventilation, and defined those who stayed less than 7 days as short-term ventilation group and those who stayed longer than 7 days as long-term ventilation group. He showed that the number of rib fractures was statistically significant in patients in the long-term mechanical ventilation group, that GCS was below 8 and mortality rates were higher. In our study, we showed that the risk of mortality increases statistically significantly as the duration of stay in the mechanical ventilator increases.

In conclusion, trauma is an important health problem because it ranks first among youth deaths. Thoracic traumas occupy a significant place in deaths due to trauma. APACHE II and GCS systems have an important role in predicting mortality in patients treated in intensive care unit due to trauma. Therefore, intensive care follow-ups and treatments should be planned accordingly by considering the high risk of mortality in patients with high APACHE II score and low GCS score.

Ethics Committee Approval: Ethics committee approval was received for this study from Balıkesir University School of Medicine Clinical Research Ethics Committee (2018/151).

Informed Consent: Due to the retrospective design of the study, informed consent was not taken.

Peer-review: Externally peer-reviewed.

Author Contributions: Concept - M.K., Z.Ö., C.B.; Design - M.K., C.B.; Supervision - M.K., Z.Ö., C.B.; Resources - M.K., Z.Ö., C.B.; Materials - M.K., Z.Ö., C.B.; Data Collection and/or Processing - Z.Ö.; Analysis and/or Interpretation - M.K., Z.Ö., C.B.; Literature Search - M.K., Z.Ö., C.B.; Writing Manuscript - M.K., Z.Ö., C.B.; Critical Review - M.K., Z.Ö., C.B.

Conflict of Interest: Authors have no conflicts of interest to declare.

Financial Disclosure: The authors declared that this study has received no financial support.

\section{REFERENCES}

I. Kara I, Altınsoy S, Gök U, Onur A, Sarıbapıcçı R. Mortality analysis of trauma patients in general intensive care unit of a state hospital. J Turk Soc Intens Care 2015; 13: 68-74. [Crossref]

2. Yıldırım F, Kara I, Küçük H, Karabıyık H, Katı I. Evaluation of scoring systems in trauma patients for intensive care mortality. GKDA Derg 2016; 22(I): 29-33. [Crossref]

3. Polinder S, Meerding WJ, van Baar ME, et al. Cost estimation of injury-related hospital admissions in 10 European countries. J Trauma 2005; 59(6): 1283-90. [Crossref]

4. World Health Organization,Violence and injuries: the facts (2010). Available From: URL: http://whqlibdoc.who.int/ publications/2010/978924l599375_eng.pdf

5. Emircan Ș, Özgüç H, Aydın Ș, Özdemir F, Köksal Ö, Bulut M. Factors affecting mortality in patients with thorax trauma. Ulus Travma Acil Cerrahi Derg 20II; 17(4): 329-33. [Crossref]

6. Ahmet R, Karagulle E, Karakaya K, Gokce F, Abcı I. Our trauma cases of the last nine years. Ulus Travma Acil Cerrahi Derg 200I; 7: 91-5.

7. Karabıyık L. Intensive care scoring systems. Yoğun Bakım Dergisi 2010; 9(3): 129-43.

8. Julian G, Lynn C. Huffman, et al. Blunt and penetrating injuries of the chest wall, pleura, and lungs. General Thoracic Surgery, 7th ed. 2009. Lippincott Williams $₫$ a Wilkins, 2009.p.891-902.

9. Ludwig C, Koryllos A. Management of chest trauma. J Thorac Dis. 2017; 9(3): 172-7. [Crossref]

10. T.C. Türkiye İstatistik Kurumu Bașkanlığı (TÜiK) Haber Bülteni. Ölüm Nedeni İstatistikleri, 2013. Sayı: 16162. OI Nisan 2014.

II. Akturan S, Gümüș B, Özer Ö, Balandız H, Erenler AK. Death rates and causes of death in Turkey between 2009 and 2016 based on TUIK data. Konuralp Tip Dergisi 2019; II(I): 9-16. [Crossref] 
12. Lin FCF, Tsai SCS, Li RY, Chen HC, Tung YW, Chou MC. Factors associated with intensive care unit admission in patients with traumatic thoracic injury. JIMR 20I3; 4I(4): I3I0-7. [Crossref]

13. O'Connor JV, Adamski J. The diagnosis and treatment of non-cardiac thoracic trauma. J R Army Med Corps 20I0; 156: 5-I4. [Crossref]

14. Stewart RM, Corneille MG. Common complications following thoracic trauma: their prevention and treatment. Semin Thorac Cardiovasc Surg 2008; 20: 69-7I. [Crossref]

15. Pogorzelski GF, Silva TAAL, Piazza T, Lacerda TM, Netto FACS, Jorge AC, Duarte PAD. Epidemiology, prognostic factors and outcome of trauma patients admitted in Brazilian intensive care unit. Open Access Emerg Med 2018; 10: 81-8. [Crossref]

16. Abolfotouh MA, Hussein MA, Abolfotouh SM, Al-Marzoug A, AlTeriqi S, Al-Suwailem A, et al. Patterns of injuries and predictors of in hospital mortality in trauma patients in Saudi Arabia. Open Access Emerg Med 2018; 10: 89-99. [Crossref]

17. Moon SH, Kim JW, Byun JH, Kim SH, Choi JY, Jang IS, et al. The thorax trauma severity score and the trauma and injury severity score: Do they predict in-hospital mortality in patients with severe thoracic trauma? Medicine (Baltimore) 2017; 96(42): e8317. [Crossref]
18. Okabe Y. Risk factors for prolonged mechanical ventilation in patients with severe multiple injuries and blunt chest trauma: a single center retrospective case-control study. Acute Med Surg 2018; 5: 166-72. [Crossref]

19. Cullen DJ, Civetta JM, Briggs BA, Ferrara LC. Therapeutic intervention scoring system: a method for quantitative comparison of patient care. Crit Care Med 1974; 2: 57-60. [Crossref]

20. Moreno R, Morais P. Validation of a simplified therapeutic intervention scoring system on an independent database. Intensive Care Med 1997; 23: 640-4. [Crossref]

21. Knaus WA, Draper EA, Wagner DP. APACHE II: a severity of disease classification system. Crit Care Med 1985; 13: 818-29. [Crossref]

22. Ünlü AR, Ülger F, Dilek A, Barıș S, Murat N, Sarıhasan B. Evaluation of the relationship between revised trauma score, and trauma and Injury severity scores with prog-nosis of trauma patients in intensive care unit. Turk Anaesth Int Care 2012; 40(3): 128-35. [Crossref]

23. Dur A, Cander B, Koçak S, Girișgin S, Gül M, Koyuncu F. Multiple trauma patients and trauma scoring systems in emergency intensive care unit. JAEM 2009; 8(4): 24-7. 